\title{
Subpoblaciones neuronales presentes en el ganglio de la raíz dorsal
}

\author{
Marlén Martínez, Niyibi Y. Quiroga, Jaime E. Castellanos; Hernán Hurtado \\ Laboratorio de Neurociencias, Instituto Nacional de Salud, Bogotá, D.C., Colombia
}

\begin{abstract}
La función principal de las neuronas del ganglio de la raíz dorsal (GRD) es transmitir la información sensorial desde la periferia hasta el sistema nervioso central. Dos clases de células están presentes en el ganglio: las células no neuronales y las neuronales. La heterogeneidad morfológica, fisiológica y bioquímica de la población neuronal permite diferenciarla en subpoblaciones. Morfológicamente, se distinguen tres tipos neuronales (A, B y C) según el tamaño y las características ultraestructurales. Fisiológicamente, hay una relación directa entre el tamaño, el diámetro de las fibras nerviosas y la velocidad con que conducen el impulso nervioso. Finalmente, el uso de marcadores (neuropéptidos, enzimas, receptores, etc.) permite realizar una clasificación bioquímica, que es la más utilizada para estudiar la función neuronal. Este artículo revisa la evidencia experimental sobre el tema de la heterogeneidad neuronal del GRD y presenta una correlación desde el punto de vista bioquímico y fisiológico en los casos en donde hay información disponible. El estudio de subpoblaciones en este ganglio resulta de bastante interés para investigaciones en neurociencias, principalmente en infecciones por virus neurotrópicos, traumatismos del nervio periférico y el estudio de factores neurotróficos, entre otros.
\end{abstract}

Palabras clave: ganglio de la raíz dorsal, ganglio espinal, neuronas sensitivas, neurotransmisor, neurotrofina.

\section{Neuronal subpopulations present in the dorsal root ganglion}

Dorsal root ganglion (DRG) neurons main function is to convey sensory information from the periphery towards the central nervous system. Two kinds of cells are present in this ganglion: non-neuronal cells and neurons. Morphological, functional and biochemical heterogeneity of the neuronal population makes it necessary to distinguish cellular subpopulations. There are three types of DRG neurons morphologically defined (A, B and C), according to their size and ultrastructural characteristics. There is a direct correlation between cell size, diameter of the fibers and conduction velocity. Finally, a number of markers such as neuropeptides, enzymes and receptors allow for a biochemical classification which is the most used for the study of the neuronal function. This paper reviews the experimental evidence on DRG neurons heterogeneity and presents a biochemical and physiological correlation in the cases when relevant information is available. Study of DRG neuron populations is relevant to different fields in neuroscience research, such as the study of neurotropic virus infection mechanisms, cellular and molecular biology of peripheral nerve injury and neurotrophic factors, among others.

Keywords: dorsal root ganglion, spinal ganglion, sensory neurons, neurotransmitters, neurotrophin.

Los ganglios de la raíz dorsal (GRD), también llamados ganglios espinales o sensitivos, son

\footnotetext{
Correspondencia:

Jaime E. Castellanos, Laboratorio de Neurociencias, Instituto Nacional de Salud, Apartado aèreo 80080, Bogotá, D.C., Colombia; jcastellanos@hemagogus.ins.gov.co

Recibido: 08/05/00; aceptado: 21/07/00
}

protuberancias ubicadas en la raíz dorsal de la médula espinal y están formados por células neuronales y no neuronales. Se localizan en los agujeros intervertebrales de la columna y se distribuyen en cervicales, torácicos, lumbares, sacros y coccígeos. Las neuronas que los forman son exclusivamente sensitivas, de tipo bipolar o 
seudomonopolar, que evolucionan a partir de neuroblastos bipolares provenientes de la cresta neural. Las fibras de las neuronas, luego de su nacimiento, se dividen en dos ramas divergentes, una medial o central y otra lateral o periférica. Las ramas mediales forman la raíz dorsal, la cual penetra en la médula a través del surco lateral dorsal y alli establece conexión con neuronas presentes en el asta dorsal. Por su parte, las ramificaciones periféricas de cada ganglio se unen a la raíz ventral medular formando el nervio raquídeo o mixto y, luego, se dirigen a la periferia para terminar en los distintos receptores sensitivos ya sean cutáneos, musculares, articulares o viscerales (figura 1). Estos receptores sensoriales pueden ser terminaciones libres o estar encapsuladas por células especializadas, cuya función es captar y convertir los estímulos del medio en impulsos nerviosos aferentes. Las neuronas del ganglio tienen como función convertir los estímulos sensoriales externos en señales nerviosas y transmitirlas hasta el sistema nervioso central (SNC), en donde son integradas y se efectúa una respuesta (1).

Histológicarnente, las poblaciones celulares más comunes en el ganglio son las neuronas, los fibroblastos, las células satélite y las células de Schwann. Estas dos últimas están muy relacionadas ya que las células satélite, bajo ciertas condiciones, pueden adquirir la morfología y desempeñar las funciones de las células de Schwann. Las células satélite envuelven cada

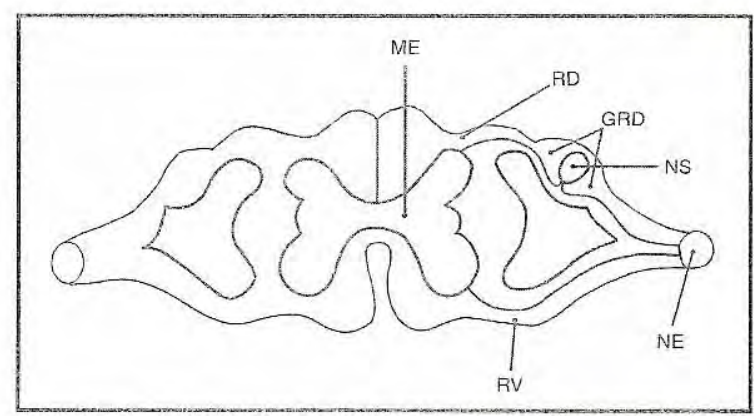

Figura 1. Los GRD están ubicados en la raiz posterior o dorsal (RD) de la médula espinal (NiE). Las neuronas que los forman son seudomonopolares de tipo sensitivo (NS). Las fibras de estas neuronas se dividen en dos ramas divergentes, una central que se dirige hacia la médula espinal y otra periférica que se une a la raiz ventral (RV) de la $M E$ formando el nervio espinal (NE). neurona sensitiva del ganglio. Por otro lado, las células de Schwann, que son la glía del sistema nervioso periférico (SNP), se encuentran asociadas a los axones, envolviendo varios en su citoplasma (en el caso de fibras no mielínicas) o rodeando un solo axón, formando una vaina de mielina característica. Las funciones que cumplen estas células gliales son principalmente de protección y soporte metabólico neuronal y axonal. Los fibroblastos, por otro lado, son los productores de la matriz extracelular presente en el tejido conjuntivo del ganglio (2). Por su parte, las neuronas presentes en los ganglios son exclusivamente de tipo aferente sensitivo y participan en la transmisión de la información sensorial desde la periferia hasta el SNC, en donde inician las respuestas voluntarias e involuntarias. Esta información se clasifica de acuerdo con el lugar de origen en exterocepción, cuando es captada por los órganos de los sentidos o la piel, e interocepción, cuando se origina en músculos y vísceras (3).

\section{Clasificación de subpoblaciones neuronales}

Las neuronas sensitivas son diferentes morfológica, bioquímica y funcionalmente, lo que permite clasificarlas en poblaciones y eventualmente en subpoblaciones. Es posible que esta diversidad resulte de diferencias inducidas genética o epigenéticamente; sin embargo, los factores que la originan hasta ahora son inciertos (4).

\section{Clasificación morfológica}

La primera clasificación neuronal, realizada en ratas, se basó en el tamaño de los somas al ser vistos en el microscopio de luz, dividiéndolas en dos categorías principales, las neuronas tipo A (grandes y claras) y las tipo B (pequeñas y oscuras). Unos años más tarde, utilizando microscopía de contraste de fases y electrónica, se confirmaron estos hallazgos y se pudo hablar de subpoblaciones, basadas solamente en la apariencia de la sustancia de Nissl (SN), formada por cúrmulos de retículo endoplásmico rugoso. Así se demostró que las neuronas tipo A presentaban cúmulos de esta sustancia en la periferia del pericarión, separados por hilos angostos de neuroplasma, mientras que en las tipo $B$ se encontraba relativamente compacta y libre de 
separaciones citoplasmáticas. A su vez, se dividió cada tipo neuronal en subtipos $\left(A_{1}, A_{2}, A_{3}\right.$ y $B_{1}$, $B_{2}, B_{3}$ ) según la distribución de la $S N$ en el citoplasma. Con la estructura del aparato de Golgi y sus patrones de impregnación con osmio yodado de zinc, se realizó otra clasificación, adicionando un tercer grupo (las neuronas tipo C), las más pequeñas dentro del ganglio (5). El estudio ultraestructural de estas tres poblaciones se amplió unos años más tarde con observaciones adicionales con microscopio electrónico de organelos citoplasmáticos como el complejo de Golgi, el retículo endoplásmico y las mitocondrias (6).

En 1985, Sommer y colaboradores realizaron un estudio en ratón y clasificaron las neuronas en tres tipos y siete subtipos combinando ultraestructura y citoquímica. Se describió, así, que las neuronas tipo A tenían gran actividad de anhidrasa carbónica (AC) y acumulaban el neurotransmisor glutamina, contrario a lo que sucedía con las tipo B; las tipo C, por otro lado, presentaban actividad de fosfatasa ácida y alta afinidad por la glutamina (7). Los porcentajes de distribución de cada subpoblación se muestran en el cuadro 1.

Cuadro 1. Porcentaje de neuronas sensoriales en el GRD in vivo, distribuido según subtipos.

\begin{tabular}{lcccccccc}
\hline Tipo neuronal & A1 & A2 & A3 & B1 & B2 & B3 & C & Ref. \\
\hline Rata & 23 & 2 & 8 & 56 & 10 & 1 & - & 5 \\
Rata & 31 & 8 & 5 & 40 & 10 & 4 & 2 & 6 \\
Ratón & 12 & 16 & 8 & 50 & 8 & 4 & 1 & 7 \\
\hline
\end{tabular}

Estos tipos neuronales ( $\mathrm{A}, \mathrm{B}$ y $\mathrm{C}$ ) corresponden por tamaño a las neuronas grandes, intermedias y pequeñas, los cuales varían según especie, edad y condiciones (in vivo e in vitro) y son clasificados por cada autor dependiendo de los tamaños encontrados en sus estudios (cuadro 2). Sin embargo, todos coinciden en afirmar que la población más abundante en el ganglio corresponde a la de neuronas de diámetro pequeño e intermedio, debido, probablemente, a que durante el desarrollo los precursores de las neuronas grandes detienen su división mucho antes que los de las neuronas pequeñas (8).

En GRD aviares embrionarios hay dos subpoblaciones neuronales definidas por el momento de su diferenciación, su localización dentro del ganglio y su tamaño: las neuronas de temprana diferenciación ventrolaterales, grandes, y las neuronas de diferenciación tardía dorsomediales, pequeñas; sin embargo, esta diferenciación de grandes y pequeñas parece existir solamente en el período de incubación porque se pierde luego de su nacimiento (9).

\section{Clasificación fisiológica}

Según el lugar en la periferia de donde provengan las aferencias primarias, éstas se dividen en musculares, cutáneas y viscerales. En ambos grupos encontramos fibras mielínicas distribuidas en los grupos I, II y III y amielínicas del grupo IV. Hay una estrecha relación entre la modalidad sensorial y el tipo de fibra que la conduce. El dolor y la temperatura (nocicepción y termorrecepción) se conducen principalmente por fibras tipo III y

Cuadro 2. El diámetro neuronal es el criterio más utilizado para clasificar las neuronas sensoriales en el GRD. Basados en este criterio, se encuentran tres subtipos de neuronas: pequeñas, intermedias y grandes. El diámetro en $\mu \mathrm{m}$ de cada subtipo depende de la especie del animal y de la clase de estudio (in vivo e in vitro).

\begin{tabular}{|c|c|c|c|c|c|c|}
\hline Diámetro & Estudio in vivo & Estudio in vitro & Pequeñas $(\mu \mathrm{m})$ & Medianas $(\mu \mathrm{m})$ & Grandes $(\mu \mathrm{m})$ & Ref. \\
\hline \multirow[t]{5}{*}{ Rata adulta } & $x$ & & $<35$ & $\longrightarrow$ & $>35$ & 6 \\
\hline & $x$ & & $<30$ & - & $>30$ & 39 \\
\hline & $x$ & & $<25$ & $25-40$ & $>40$ & 40 \\
\hline & $x$ & & $<30$ & $30-45$ & $>45$ & 45 \\
\hline & $x$ & & $<45$ & $\longrightarrow$ & $>45$ & 48 \\
\hline \multirow[t]{2}{*}{ Rata neonatal } & & $x$ & $<15$ & $15-26$ & $>26$ & 18 \\
\hline & & $x$ & $<17$ & $17-25$ & $>25$ & 44 \\
\hline \multirow[t]{2}{*}{ Ratón adulto } & $x$ & & $<20$ & $20-35$ & $>35$ & 7 \\
\hline & & $x$ & $<15$ & $15-25$ & $>25$ & 58 \\
\hline Humano & $x$ & & $<25$ & $25-50$ & $>50$ & 13 \\
\hline
\end{tabular}


IV, las sensaciones mecánicas (mecanorrecepción) por las fibras tipo $I I$ y IV y los estimulos propioceptivos por las fibras de los grupos I y II (10). Al combinar el tipo de fibra que conduce el impulso nervioso con los diferentes tipos de canales iónicos presentes, podemos dividir las neuronas en tres grupos: las neuronas $F$ conducen los impulsos nerviosos con fibras de los grupos II y lil y su potencial de acción (PA)es sensible a la tetradotoxina (TTX); las neuronas A conducen con fibras del grupo IV y su PA es TTXsensible mediado por iones sodio; y las neuronas $\mathrm{H}$ conducen con axones de los grupos III y IV y su PA es TTX-resistente mediado por iones sodio y calcio $(10)$.

Se ha informado también que el calibre de las aferencias sensoriales, así como la velocidad de conducción (VC) del impulso nervioso, deperiden del tamaño neuronal. Las neuronas más grandes en el ganglio tienen fibras mielínicas y las más pequeñas tienen fibras amielínicas. Dependiendo de la VC ( $\mathrm{m} / \mathrm{seg})$, en rata se han descrito cuatro tipos de fibras: $A \alpha(V C>30 \mathrm{~m} / \mathrm{seg}), A \beta(13-29 \mathrm{~m} /$ seg), $A \delta(1,4-12 \mathrm{~m} / \mathrm{seg})$ y $C(<1,3 \mathrm{~m} / \mathrm{seg})(11,12)$. Las fibras $A \alpha / \beta$ (mielínicas) son consideradas como un solo grupo y están presentes únicamente en neuronas de gran tamaño, las $C$ (amielínicas) sólo están presentes en neuronas de pequeño diámetro y las A $\delta$ están presentes en neuronas de todos los tamaños. Todo esto demuestra una relación directa entre el tamaño neuronal, el tipo de fibra, la presencia o ausencia de mielina y la VC (11).

\section{Clasificación bioquímica}

Las técnicas inmunocitoquímicas son las más empleadas para estudiar la presencia de péptidos, enzimas y carbohidratos y la hibridación in situ para la detección de ARNm específicos.

\section{Filamentos neuronales}

El citoesqueleto de las neuronas está formado por tres grupos de filamentos que se clasifican según su diámetro en microtúbulos o neurotúbulos (con diámetro de $25 \mathrm{~nm}$ ), filamentos intermedios o neurofilamentos (diámetro de $10 \mathrm{~nm}$ ) y microfilamentos (con diámetro de $5 \mathrm{~nm}$ ) (13). Los neurofilamentos son proteinas altamente conservadas a través de un amplio rango de especies, lo que parece indicar que su presencia es de vital importancia en la organización del sistema nervioso sensorial (14).

\section{Neurofilamentos}

Los neurofilamentos (NF) son proteínas estructurales que hacen parte de los filamentos intermedios, que mantienen la morfología neuronal y regulan el diámetro axonal. Están constituidos por tres proteínas similares en su secuencia génica y estructura proteica primaria (15). En estudios inmunocitoquímicos, los dos principales tipos de neuronas en el ganglio espinal presentan diferencias en el contenido de NF; las neuronas tipo A son ricas en NF con un patrón de marcación intenso en forma de enrejado a través de todo el citoplasma, mientras que las tipo $B$, pobres en NF, presentan una marcación menos intensa y más difusa a través de todo el citoplasma (16).

Estudios hechos en ganglios humanos han encontrado que existen dos poblaciones neuronales, una rica en NF (que equivale a $45 \%$ de la población neuronal total) formada principalmente por neuronas de gran tamaño y una pobre en NF formada por neuronas pequeñas $e$ intermedias (17).

La presencia de NF no sólo está relacionada con el tamaño celular sino también con la VC. Utilizando el anticuerpo RT97 dirigido contra la fracción fosforilada de los neurofilamentos, las neuronas positivas tienen fibras $A \alpha / \beta$ y $A \delta$, mientras que las neuronas negativas tienen fibras C. Como se sabe que las fibras $A \alpha / \beta$ y $A \delta$ son mielínicas y $R T 97(+)$ y que las fibras $C$ son amielínicas y RT97 (-), es posible que haya una relación directa entre las presencia de NF y el estado de mielinización $(11,14)$.

\section{Periferina}

Otra proteina que hace parte de los filamentos intermedios es la periferina. Utilizando un anticuerpo (Ac) específico contra ella, se ha demostrado que presenta una marcación recíproca a la presentada por NF. En GRD humano, $54 \%$ del total neuronal presenta inmunorreactividad para este Ac con predominio de neuronas pequeñas, que corresponden en 
distribución de tamaño a la población pobre en NF. Là función de este filamento intermedio es incierta (17).

\section{Neuropéptidos}

Son los marcadores bioquímicos más empleados para clasificar poblaciones neuronales en el GRD. Forman parte de un grupo heterogéneo de proteínas que cumplen principalmente tres funciones. Una función neurotransmisora que participa en la transmisión de la información sensorial por medio de impulsos nerviosos desde la periferia hasta el SNC (18); una función inflamatoria neurogénica, que comprende el aumento en la liberación de histamina por monocitos, la regulación del flujo sanguíneo cutáneo y la inducción de edema y eritema; y, finalmente, una función inmunológica, que actúa como factores quimiotácticos y mitóticos sobre las células inmunes (19). Por el aumento que presentan algunos neuropéptidos luego de una lesión de nervio ciático, se cree que podrían estar también participando como factores tróficos que ayudan al proceso de regeneración; sin embargo, esto hasta ahora es incierto (20). Como marcadores de poblaciones en el GRD, se encuentran distribuidos en neuronas de todos los tamaños, pero algunos de forma preferencial en subpoblaciones específicas.

\section{Sustancia P}

La sustancia P (SP) fue el primer neuropéptido descrito en el ganglio espinal y el primero en ser determinado como neurotransmisor. Los estudios concuerdan en afirmar que está presente principalmente en neuronas de diámetro pequeño e intermedio, pero difieren al hablar de los porcentajes de expresión neuronal. En rata adulta, in vivo, los porcentajes varían entre $15 \%$ en un ganglio espinal inespecífico, y $30 \%$ en L5 $(21,22)$. Estas variaciones se deben, probablemente, al nivel espinal del ganglio, por ejemplo, en L5, 30\% de la población total es inmunorreactiva para SP y en C1 sólo $11 \%$. El mayor porcentaje de neuronas que contiene SP se encuentra en la región lumbar y disminuye en los niveles anteriores. Esto también sucede con otros neuropéptidos como el péptido intestinal vasoactivo (23).
En tejido humano obtenido postmortem de personas mayores de 60 años, el porcentaje de neuronas inmunorreactivas para SP es de $44 \%$, un porcentaje mucho mayor al encontrado en ratas. En este caso, se ha planteado que el envejecimiento produzca la muerte de neuronas sensoriales de gran tamaño, lo que aumentaría el número de neuronas de pequeño tamaño con relación a la población total y, al mismo tiempo, hace que se aumente el porcentaje de neuronas positivas para SP (17). Sin embargo, la ausencia de controles jóvenes en este estudio impide ser categóricos a este respecto.

In vitro, por el contrario, el número de neuronas positivas para SP y otros neuropéptidos, como el péptido relacionado con el gen de la calcitonina (CGRP), disminuye (28 y $37 \%$, respectivamente) por la ausencia de factores tróficos, como el factor de crecimiento nervioso (NGF) en el medio de cultivo, que in vivo son suministrados por el blanco periférico, pero que no están presentes en el cultivo y cuya función en parte es mantener el fenotipo neuronal (24-26). Adicionalmente, se ha visto que, en cultivo de ratón neonatal, si se adiciona al medio NGF, el porcentaje de inmunorreactividad (IR) para SP vuelve a sus niveles normales (8).

De las neuronas positivas para SP en ratas (18$20 \%$ ), $30 \%$ son grandes y RT $97+$, mientras que $70 \%$ son pequeñas y RT97-. Las neuronas que poseen este péptido tienen $\mathrm{VC}$ que van desde 0,5 hasta $9,5 \mathrm{~m} / \mathrm{seg}$, lo que indica que sólo está presente en neuronas con fibras $A \delta$ y C (en 20 y $30 \%$, respectivamente) $(14,27)$.

\section{Péptido relacionado con el gen de la calcitonina}

Entre 45 y $50 \%$ del total de neuronas del GRD de rata presenta inmunorreactividad para este péptido distribuida en todos los tamaños, pero con un mayor porcentaje en neuronas pequeñas $(22,28)$.

Estudios de doble inmunodetección entre SP y CGRP han mostrado una alta asociación entre estos dos péptidos, lo que sugiere una asociación fisiológica desde el punto de vista farmacológico, ya que ambos péptidos comparten funciones. Además, se sabe que CGRP puede inhibir una endopeptidasa para SP, previniendo así, en parte, su degradación y prolongando su acción (22). 
En estudios realizados en ratas, de las neuronas positivas para CGRP (43-46\%), 32\% son grandes y RT97+, mientras que $68 \%$ son pequeñas, RT97y tienen VC que van de 0,5 a $28 \mathrm{~m} / \mathrm{seg}$, lo que sugiere que el impulso nervioso se conduce con fibras de todos los tipos ( $A \alpha / \beta, A \delta$ y $C$ en 33,46 y $17 \%$, respectivamente); esto concuerda con los datos de presencia de CGRP en neuronas de todos los tamaños aunque con cierta preferencia por las neuronas pequeñas $(28,14)$.

\section{Somatostatina}

Es otro péptido localizado en neuronas pequeñas principalmente e involucrado en la neurotransmisión termorreceptiva. Entre 10 y $20 \%$ de la población neuronal total es positiva para este péptido en el GRD $(16,24)$. En cultivo se presenta una disminución $(<10 \%$ ) y, a pesar de la administración de NGF, los niveles de somatos-tatina (SOM) no vuelven a sus porcentajes normales, contrario a lo que pasa con SP y CGRP (25). No hay diferencia en los porcentajes de marcación en distintos niveles espinales. A diferencia de SP y CGRP, que están presentes prácticamente en la misma población neuronal, SOM no 'colocaliza' con ninguno de estos péptidos, lo que determina que hay dos subpoblaciones de neuronas pequeñas que utilizan, por lo menos, tres diferentes neurotransmisores (29). El impulso nervioso de las neuronas que poseen SOM sólo se conduce por fibras tipo C (13\%) (14).

\section{Otros neuropéptidos}

En estudios realizados en rata in vivo, se ha encontrado que el péptido intestinal vasoactivo (VIP), el neuropéptido Y (NPY) y la galanina (GAL); se encuentran principalmente en neuronas de gran diámetro y en porcentajes menores de $10 \%$ para VIP y NPY y de $15 \%$ para GAL $(22,23,30)$. Estos porcentajes se aumentan cuando hay lesión de nervio ciático o en cultivo, llegando casi a $50 \%$ $(25,26)$, lo que hace pensar que in vivo, al igual que con SP, hay factores en el blanco que están manteniendo el fenotipo neuronal y el aumento de estos péptidos post-lesión podría estar indicando que actúan como factores que promueven la regeneración sin que esto haya sido demostrado (31).

\section{Enzimas}

\section{Tirosina hidroxilasa}

Usando antisueros contra tirosina hidroxilasa (TH) y dopamina $\beta$ hidroxilasa (DBH), dos enzimas específicas para céluias catecolaminérgicas, se logró demostrar que una población de neuronas de GRD en rata es catecolaminérgica y que el neurotransmisor que producen es la dopamina. Los resultados mostraron que el antisuero anti-TH marcó una subpoblación muy pequeña de neuronas sensoriales, dependiendo del nivel espinal del ganglio. En el ganglio L5, 1\% de las neuronas eran positivas para anti-TH, mientras que en L5 y $\$ 1$ sólo eran positivas $0,1 \%$ y no se presentó IR en ganglios cervicales, torácicos y lumbares del 1 al 4. Las neuronas positivas eran de diámetro pequeño. Con anti-DBH no se marcaron neuronas sensoriales pero algunas de sus fibras sí, lo que hace pensar que una pequeña porción de neuronas en algunos GRD de rata es $\mathrm{TH}(+)$ y DBH(-) con probabilidad de ser dopaminérgicas. En cultivos de GRD de embriones de rata de 16 días (o de embriones de pollo de 8-12 dias), menos de $5 \%$ de neuronas son $\mathrm{TH}(+)$ después de mantenerlas 24 horas in vitro. Por el diámetro de estas neuronas, se cree que pueden estar involucradas en las vias de dolor y temperatura (32).

\section{Fostatasa ácida resistente al fuoruro (FARF)}

Es una isoenzima de la fosfatasa ácida, presente en una subpoblación de neuronas pequeñas que forma de 32 a $35 \%$ de la población neuronal total en ganglio de rata (21). A pesar de que las neuronas FARF positivas son de tamaño pequeño, éstas no contienen SP o SOM, también marcadores de esta población neuronal (29).

\section{Colinavacetiltransferasa}

Para identificar si hay una subpoblación neuronal colinérgica en el GRD de rata, se utilizó un AC dirigido contra la enzima colina-acetiltransferasa, marcador específico de células colinérgicas. La IR está presente en $66 \%$ de las neuronas de diámetro pequeño del GRD L1 y es dependiente de la edad: en ratas jóvenes, prácticamente todas las neuronas de este tamaño son positivas, en 
tanto que en ratas viejas la IR se reduce a $61 \%$. De acuerdo con este y otros estudios, en los que se ha encontrado actividad de acetilcolinesterasa en $50 \%$ de las neuronas (con predominio de neuronas pequeñas y medianas), se ha sugerido que hay una subpoblación de neuronas en el ganglio espinal que usan la acetilcolina como neurotransmisor y que adicionalmente tienen la capacidad de sintetizarla (33). Sin embargo, esta función de la acetilcolina en las neuronas sensoriales de ganglio de la raíz dorsal es aún muy controvertida.

\section{Anhidrasa carbónica}

Hasta 1983, se afirmaba que la presencia de AC era exclusiva de algunas células gliales y que las células neuronales de ganglio sensorial no la poseían. Un método mejorado de microscopía electrónica demostró que había una localización muy selectiva e inusual de actividad enzimática en neuronas de ganglio espinal de rata. En este ensayo, aproximadamente $30 \%$ del total neuronal presentaba actividad de esta enzima con predominio en células grandes e intermedias y ausencia total en neuronas pequeñas. La función de esta enzima en estas neuronas es incierta; sin embargo, como las neuronas son tan activas metabólicamente, es probable que se requiera en procesos como hidratación del $\mathrm{CO}_{2}$ (originado posiblemente en reacciones de decarboxilación en la síntesis de neurotransmisores) y facilitando también su salida de la célula. Se piensa, también, que la enzima ayuda a mantener los niveles de cloro intracelular en las células ganglionares y regula el $\mathrm{pH}$ intracelular necesario para actividades metabólicas como glicólisis o entrada de calcio. Se propone, así mismo, que podría estar controlando la concentración intracelular de $\mathrm{H}^{+} \mathrm{y}$ $\mathrm{Cl}^{-}$en la neurona. También se ha detectado por citoquímica en ganglios espinales de ratón, hallazgo que se correlaciona con su presencia por inmunohistoquímica $(7,34,35)$. 62,32 y $38 \%$ de las neuronas con fibras $A \alpha / \beta, A \delta$ y $C$ presentan actividad de $A C$, lo que refuerza la presencia de esta enzima de manera preferencial en las neuronas de gran tamaño (34).

\section{Prostaglandina $D$ sintetasa}

La prostaglandina $D_{2}\left(P G D_{2}\right)$ es un neuro- modulador cuya síntesis es mediada por la prostaglandina D sintetasa. Actúa sobre fibras nociceptivas tipo $C$, inhibiendo la conducción de potasio activada por calcio. En cortes de GRD de pollo se logró detectar una subpoblación de neuronas que conservan la actividad de esta enzima y son capaces de sintetizar $\mathrm{PGD}_{2}$. Por su tamaño y características ultraestructurales pertenecen a la subclase $\mathrm{B} \alpha$. Este hallazgo se relaciona con la función ejercida por la $\mathrm{PGD}_{2}$ sobre la nocicepción, cuando estimula la liberación de taquicininas como SP (36).

\section{Receptores}

\section{Receptores para neurotrofinas}

Las neurotrofinas son un grupo heterogéneo de proteínas codificadas por genes diferentes que promueven la diferenciación, la supervivencia y el mantenimiento de ciertas neuronas centrales y periféricas. Los miembros más conocidos de esta familia son el factor de crecimiento nervioso (nerve growth factor, NGF), la neurotrofina 3 (neurotrophin 3 , NT-3) y el factor neurotrófico derivado del cerebro (brain derived neurotrophic factor, BDNF) (37). Se sabe que, durante el desarrollo, cada tejido produce un factor neurotrófico diferente y las neuronas que hacen contacto con su blanco periférico sobreviven, las que no, sufren apoptosis (38). En la madurez, el órgano blanco mantiene el correcto funcionamiento de las neuronas que lo inervan. Estas funciones ejercidas por las neurotrofinas son dependientes de la presencia de receptores específicos para ellas y de su transporte retrógrado. Existen dos tipos de receptores, los de alta afinidad, que poseen un dominio de tirosina-cinasa intracelular (trkA para NGF, trkB para BDNF y trkC para NT-3) y el de baja afinidad (p75), que une las tres neurotrofinas con similar afinidad. Los dos tipos de receptores están presentes en las neuronas del GRD. En rata (in vivo), $40 \%$ de las neuronas son IR para un $A C$ anti-trkA y prácticamente todas ellas son CGRP positivas (marcador de neuronas pequeñas) (39). Estos datos son consistentes con los porcentajes de neuronas que tienen ARNm para trkA (de 35 a $40 \%$ ). Los otros dos receptores de alta afinidad (trkB y trkC) se encuentran entre 5 y $7 \%$ y entre 15 y $17 \%$ de las neuronas totales en el ganglio 
con mayor predominio de las neuronas de tamaño intermedio y grande, respectivamente $(40,41)$. Las técnicas de doble marcaje para los receptores de alta y baja afinidad demuestran que p75 está presente en $90 \%$ de la población neuronal y que todas las neuronas positivas para los trk 'colocalizan' con $p 75$, lo que sugiere que el receptor de baja atinidad puede estar asociado con la formación de los receptores de alta afinidad o puede estar involucrado en su funcionalidad (40). También se conoce que la expresión de estos receptores se regula en respuesta al daño axonal en neuronas sensoriales de rata (42).

\section{Receptornicotinico de acetilicolina}

Los genes que codifican para el receptor nicotínico de acetilcolina (RNACh) han sido bien caracterizados. Hay 5 que codifican para subunidades de tipo muscular $(\alpha 1, \beta 1, \delta, \gamma$ y $\varepsilon)$ y 11 genes que codifican para subunidades de tipo neuronal $(\alpha 2, \alpha 3, \alpha 4, \alpha 5, \alpha 6, \alpha 7, \alpha 8, \alpha 9, \beta 2, \beta 3 y$ B4). En embriones de pollo, utilizando técnicas de hibridación in síu, se han encontrado en el GRD transcriptos génicos para 2 de las 11 subunidades $(\alpha 3$ y 04 ): $19 \%$ expresan ARNm para $\alpha 3$ y $8 \%$ para $\alpha A$. Esta expresión no es dependiente del desarrollo, ya que los porcentajes se mantienen en embrión y en adulto, y están distribuidos en neuronas de todos los tamaños. Con un $A c$ monoclonal que reconoce todas las subunidades del RNACh, se demostró que $16 \%$ de las neuronas son IR para este Ac (43).

\section{Canales iónicos y receptores para otros neurotransmisores}

La excitabilidad de las neuronas sensoriales puede ser modulada por cambios en la concentración de calcio intracelular libre. En neuronas de rata neoratal, se han identificado neuronas que expresan receptores para neurotransmisores que tienen la capacidad de aumentar la concentración de calcio intracelular (como la adenosina, bradicinina, capsaicina, SP). Se puede concluir que estos receptores se localizan preferencialmente en neuronas de tamaño pequeño e intermedio, implicadas en la nocicepción según su tamaño y sensibilidad a la capsaicina (44). Por otro lado, el transporte normal de calcio se realiza. a través de canales presentes en el soma neuronal. Aunque éstos se encuentran en todas las neuronas del GRD, la expresión de subtipos varía con el diámetro del soma. En neuronas pequeñas, más de $50 \%$ de las corrientes de calcio son transportadas a través de canales tipo L, 33\% por canales tipo $\mathrm{N}$ y $17 \%$ no usa ninguno de los dos. En neuronas grandes, solo $20 \%$ se transporta por canales tipo $\mathrm{C}$ y el resto no usa ninguno de los dos tipos. Estos hallazgos indican que el transporte de calcio está regulado por subtipos de canales dependiendo del tamaño neuronal (45).

\section{Receptor para gilucocorticoides}

EI GRD de rata muestra la coexistencia de neuropéptidos y receptor para glucocorticoides (RG). $36 \%$ de las neuronas que expresan SP, $30 \%$ de las neuronas que expresan CGRP y $50 \%$ de las que expresan GAL, 'colocalizan' con RG y no hay 'colocalización' con SOM y NPY. Esto indica que es probable que una subpoblación definida de neuronas sensoriales esté directamente influida por la acción de los glucocorticoides. Los glucocorticoides se asocian a los procesos antiinflamatorios y los neuropéptidos como SP y CGRP están implicados en reacciones inflamatorias neurogénicas; por ello, se presume que los glucocorticoides podrían regular la expresión de estos neuropéptidos para ejercer su acción (46).

\section{Otras moléculas}

\section{Gutamato}

El glutamato se considera como el principal neurotransmisor de células nerviosas del ganglio sensorial de vertebrados. Su síntesis se realiza a partir de glutamina y es mediada por la glutamina sintetasa. Estudios hechos en rata, utilizando Lglutamina y L-glutamato tritiados, lograron demostrar que las células satélites acumulan selectivamente L-glutamato y $53 \%$ de ellas lo convierte en L-glutamina. Por otro lado, esta última es incorporada al pericarión neuronal y $40 \%$ de las neuronas que la captan la convierten en L.. glutamato. Esto evidencia la existencia de un ciclo glial-neuronal en el GRD, en el que el L-glutamato liberado por las neuronas es captado por las células gliales para ser convertido en L-glutamina, que luego es transportada de regreso a las neuronas en donde se convierte en L-glutamato 
para ser reutilizado y comenzar un nuevo ciclo. Como hay una acumulación de L-glutamina tritiada en las neuronas tipo $B$, seis veces mayor que la que existe en las tipo $A$, se sugiere que una subpoblación dentro de las neuronas tipo $\mathrm{B}$ usan el glutamato como neurotransmisor, similar a lo que sucede con otra subpoblación dentro de este mismo tipo de células que usan SP o SOM como péptidos neurotransmisores (47). En ratón sucede algo similar, pues la acumulación de L-glutamina tritiada es mayor en neuronas tipo $\mathrm{B} \beta$ y $\mathrm{C}$, aunque hay una acumulación moderada por parte de las neuronas tipo $A \alpha$ y $\beta$ (7). Otro estudio que soporta esta conclusión es el realizado en ratas en las cuales, utilizando un anticuerpo anti-glutamina sintetasa, se logró demostrar que 16 y $18 \%$ de las neuronas de ganglios cervicales, torácicos y lumbares, respectivamente, muestran inmunorreactividad para este anticuerpo, con predominio de las neuronas de diámetro pequeño $(30 \%$ de éstas son IR). Utilizando un Ac contra otra enzima asociada al metabolismo del glutamato (la aspartato aminotransferasa), la IR se presenta en neuronas del ganglio sin una localización diferencial o selectiva, lo que hace más fuerte la teoría de la utilización del glutamato como neurotransmisor por una subpoblación neuronal (48).

\section{Factor de liberación de la hormona del crecimiento}

En cortes de GRD se ha encontrado que la IR para el factor de liberación de la hormona del crecimiento (GRF, growth releasing factor), se presenta en menos de $1 \%$ de la población total, en neuronas de todos los tamaños con predominio de neuronas pequeñas en ganglios cervicales y torácicos. La inmunorreactividad se observa de manera difusa y granular en el citoplasma, alrededor del núcleo, sugiriendo una asociación con el complejo de Golgi. Durante el periodo prenatal, los patrones de IR a GRF no muestran cambios significativos con relación a lo observado durante el desarrollo, lo que podría indicar que GRF no es un factor esencial en los procesos de maduración de la neurona. De otra parte, es bien conocido que el GRF humano juega un papel muy importante en el control fisiológico de las funciones viscerales, por lo menos, a nivel central; por tanto, se podría especular que las neuronas pequeñas inmunorreactivas para GRF representan una subpoblación de neuronas sensoriales viscerales (49).

\section{Serotonina (5-hidroxitriptamina, 5-HT)}

Es bien sabido que la serotonina modula la información somatosensorial en la médula espinal. Por estudios de microscopía electrónica se ha detectado que hay una población de neuronas que es inmunorreactiva para $5-\mathrm{HT}$ y que tiene la capacidad de acumular el neurotransmisor. Esta capacidad es propia de terminales nerviosas serotonina positivas, ya que por este mecanismo vuelven a capturar el neurotransmisor liberado. Por otro lado, los mastocitos (células no neuronales presentes en el ganglio) también presentan reactividad para este $A c$ y tienen igualmente la capacidad de captar el isótopo. Como estas células tienen diámetros pequeños, se hace difícil diferenciarlas de las neuronas más pequeñas en el ganglio. Sólo utilizando una tinción especial con azul alciano al $1 \%$, se pueden identificar los mastocitos, ya que este colorante es captado selectivamente por ellos en $\mathrm{pH}$ ácido, mientras que las neuronas no se tiñen a este $\mathrm{pH}(1,0)$. Asumiendo que todas las células que no se tiñen con el azul alciano son neuronas, entonces un porcentaje que varía entre 7 y $9 \%$ del total neuronal del ganglio espinal utilizaría la serotonina como neurotransmisor. La presencia de serotonina en neuronas de pequeño tamaño en el ganglio espinal sugiere que esta sustancia juega un papel más directo en la transmisión sensorial nociceptiva.

\section{Moléculas en la superficie celular}

Los glicoconjugados presentes en la superficie neuronal (glicoproteínas o glicolípidos) se usan como marcadores de poblaciones específicas en el GRD y pueden ser identificados por anticuerpos o por lectinas de unión específica. Estos azúcares complejos están involucrados en el desarrollo, la guía axonal y el reconocimiento y el contacto célula-célula. Durante el desarrollo embrionario, por ejemplo, la correcta organización de las proyecciones (a nivel central y periférico), depende de la unión específica glicoconjugado-lectina endógena (51). Los glicoconjugados con series de lactosa se expresan principalmente en 
neuronas de diámetro pequeño, cuyas terminaciones centrales llegan a la lámina | y || del asta dorsal. Los que tienen series de glucosa se expresan en neuronas de diámetro intermedio y grande con proyecciones en la lámina III y IV (52). La lectina más utilizada para identificar una subpoblación especifica en el ganglio espinal es la GSA-IB4 (Griffonia simplicifolia, extraida de la soya), que se une aproximadamente a $35 \%$ de las neuronas pequeñas que poseen en su superficie residuos de $\alpha$-galactosa terminal y que no son peptidérgicas (no reactivas para SP, CGRP o trk A, pero si positivas para FARF). Estos hallazgos son similares en humano, ratón y rata (53-55).

Por otro lado, los anticuerpos dirigidos contra antígenos embrionarios de estadios específicos (SSEA3 y SSEA4) de origen lipídico, marcan en rata (in situ) 9 y $11 \%$ de la población neuronal total, respectivamente (la mayoria de diámetro intermedio y grande). En cultivo, el porcentaje de inmunorreactividad es de 7 y $14 \%$, con marcaje en soma y en neuritas (56).

\section{Importancia de las poblaciones neuronales sensoriales}

Las subpoblaciones neuronales son de interés en el estudio de la interacción entre ellas y ciertos tipos de virus. En el caso del virus de la rabia, un virus altamente neurotrópico, éste utiliza como una de las puertas de entrada al sistema nervioso central las neuronas del GRD. Cuando hay mordedura por un animal enfermo en tejido muscular o cutáneo, las terminaciones nerviosas captan el virus y lo transportan retrógradamente hacia el soma de las neuronas sensoriales y de ahí, de forma anterógrada, hacia el SNC, en donde están sus blancos principales y donde ejerce su acción patógena produciendo una encefalitis generaimente letal. Para estudiar la interacción virus-neuronas se han usado modelos in vivo e in vitro; estos últimos resultan de interés particular ya que en cultivos embrionarios y adultos (de rata y ratón, respectivamente), aunque el virus infecta tanto células no neuronales como neuronales, hay un marcado neurotropismo y la infección predomina en las neuronas de mayor tamaño $(57,58)$, lo que hace suponer que el virus prefiere una población neuronal en especial, probablemente por la presencia de receptores específicos para el virus en ella. Estudiar en este modelo la población que presenta mayor susceptibilidad al virus rábico puede, eventualmente, ayudar a dilucidar los posibles receptores que el virus usa para entrar a las neuronas, que hasta el momento no han sido definidos completamente, y aportar elementos sobre la terapia a usar en una enfermedad que, una vez alcanza el sistema nervioso central, es letal.

Por otro lado, se sabe que todas las células presentes en el ganglio juegan un papel importante en los procesos de regeneración axonal en caso de lesiones del nervio periférico. Las neuronas que han sido capaces de sobrevivir a la lesión tienen la capacidad de regenerar sus fibras nerviosas y las células no neuronales, por su lado, facilitan esta regeneración acondicionando el microambiente celular, ya sea eliminando restos celulares por fagocitosis y formando tejido cicatricial, o sirviendo de soporte físico y metabólico, produciendo factores de crecimiento y moléculas de adhesión, entre otros $(50,60)$. El primer requisito para que la regeneración se inicie es la supervivencia de la neurona luego de la lesión, que depende básicamente del tipo neuronal, de la edad y del grado y de la proximidad de la lesión al soma neuronal. En modelos experimentales de lesión del nervio ciático hay dos cambios importantes en la población neuronal: el primero, la muerte de subpoblaciones especificas (principalmente las neuronas de mayor tamaño) y, el segundo, los cambios en la expresión de marcadores bioquímicos (neuropéptidos y enzimas, principalmente). Hasta ahora los mecanismos que producen estos cambios no están del todo claros.

\section{Conclusión}

La población neuronal del GRD es heterogénea en muchos aspectos y puede ser clasificada en subpoblaciones teniendo en cuenta su maquinaria bioquímica, propiedades de membrana, conexiones periféricas y centrales y dependencia neurotrófica, lo que hace que cada subpoblación se comporte de manera diferente frente a estímulos externos e internos. Todos los datos informados en esta revisión hacen que el estudio de las subpoblaciones neuronales sea un modelo 
de bastante interés para investigaciones de diferentes orígenes, ya sea dentro del marco de las enfermedades neurodegenerativas, los traumatismos del nervio periférico o las infecciones virales, ya que la respuesta de cada subpoblación a estos factores incide de manera importante en las consecuencias que producen.

\section{Referencias}

1. Martin JH. Neuroanatomy, Text and Atlas. 2nd. Ed. Stanford: Appleton \& Lange Co.;1996;125-59.

2. De Vries A. Schwann cells proliferation. En: Dick-Thomas editors. Peripheral neuropathy. $3^{a}$. Ed. Saunders Ed;1993;Vol1,290.

3. Perl E. Function of dorsal root ganglion neurons: An overview. En: Sensory neurons: Diversity, Development and Plasticity. Scott L. Ed. 1st Ed. New York: Oxford University Press;1992;3-23.

4. Hali AK, Ai X, Hickman GE, MacPhedian SE, Nduaguda CO, Robertson LP. The generation of neuronal heterogeneity in a rat sensory ganglion. $J$ Neurosci 1997;17:2775-84.

5. Rambourg A, Clermont $\mathbf{Y}$, Beaudet A. Ultrastructural features of six types of neurons in rat dorsal root ganglia. J Neurocytol 1983;12:47-66.

6. Kai-Kai MA. Cytochemistry of the trigeminal and dorsal root ganglia and spinal cord of the rat. Comp Biochem Physiol 1989;93A:183-93.

7. Sommer E, Kazimierczak J, Droz B. Neuronal subpopulations in the dorsal root ganglion of the mouse as characterised by combination of ultrastructural and cytochemical features. Brain Res 1985;346:310-26.

8. Ninomiya T, Walter B, Droz B. Neuronal phenotypes in mouse dorsal root ganglion cell cultures: Enrichment of substance $P$ and calbindin D-28k expressing neurons in a defined medium. Int J Dev Neurosci 1994;12:99-106.

9. Maruschi M, Pourmehr K, Weston J. A monoclonal antibody (SN1) identifies a subpopulation of avian sensory neurons whose distribution is correlated with axial level. Develop Biol 1986;118:494-504.

10. Cameron AA, Leah JD, Snow PJ. The electrophysiological and morphological characteristics of feline dorsal root ganglion cells. Brain Res 1986;362:16.

11. Harper AA, Lawson SN. Conduction velocity is related to morphological cell type in rat dorsal root ganglion neurones. J Physiol. 1985;359:31-46.

12. Lawson SN, Waddell PJ. Soma neurofilament immunoreactivity is related to cell size and fibre conduction velocity in rat primary sensory neurons. $\mathrm{J}$ Physiol 1991;435:41-63.
13. Naves F, Huerta J, Garcia-Suarez O, Urdangray N, Esteban I, Del Valle $\mathrm{M}$, et al. Distribution of immunoreactivity for cytoskeletal (microtubule, microtubule-associated, and neurofilament) proteins in adult human dorsal root ganglia. Anat Rec 1996;244:24656 .

14. Lawson NS, Perry $\mathbf{M J}$, Prabhakar E, MacCarthy W. Primary sensory neurones: Neurofilament, neuropeptides, and conduction velocity. Brain Res Bull 1993 30:239-43.

15. Vickers JC, Costa M. The neurofilament triplet is present in distinct subpopulations of neurons in the central nervous system of the guinea-pig. Neuroscience 1992;49:73-100.

16. Schlaepfer WW, Lynch RG. Inmunofluorescence studies of neurofilaments in the rat and human peripheral and central nervous system. J Cell Biol 1977;74: 241-50

17. Holford LC, Case P, Lawson N. Substance P, neurofilament, peripherin and SSEA4 immunocytochemistry of human dorsal root ganglion neurons obtained from post-mortem tissue: a quantitative morphometric analysis. J Neurocitol.1994; 23:577-89.

18. Gilabert R, McNaughton, P. Enrichment of the fraction of nociceptive neurones in cultures of primary sensory neurones. J Neurosci Meth 1997;71:191-98.

19. Sanchez C, España A. Papel de los neuropéptidos en la dermatología. Rev Neurol 1997;25:s222-31.

20. Sterne GD, Brown RA, Green CJ, Terenghi G. NT-3 modulates NPY expression in primary sensory neurons following peripheral nerve injury. J Anat 1998;193:27381.

21. Kai-kai AM, Anderton BH, Kenn PA. Quantitative analysis of the interrelationships between subpopulations of rat sensory neurons containing arginine vasopressin or oxytocin and those containing substance $P$, fluorideresistant acid phosphatase or neurofilament protein. Neuroscience 1986;18:475-86.

22. Ju G, Hokfelt T, Brodin E, Fahrenkrug J, Fischer JA, Frey $\mathrm{P}$, et al. Primary sensory neurons of the rat showing calcitonin gene-related peptide inmunoreactivity and their relation to substance $\mathrm{P}$-somatostatin-, galanin-, vasoactive intestinal polypeptide- and cholecystokininimmunoreactive ganglion cells. Cell Tissue Res. 1987;247:417-31.

23. Anand P, Gibson SS, McGregor GP, Blank MA, Bocarese-Hamilton AJ, Polak JM, et al. VIP-containing system concentrated in the lumbosacral region of the human spinal cord. Nature 1983;305:143-5.

24. Lindsay RM, Harmar, AJ. Nerve growth factor regulates expression of neuropeptides genes in adult sensory neurons. Nature 1989;337:362-4.

25. Mulderry PK. Neuropeptide expression by newborn and adult rat sensory neurons in culture: Effects of nerve 
growth factor and other neurotrophic factors. Neuroscience 1994;59:673-88.

26. Schoenen J, Delree P, Leprince P, Moonen G. Neurotransmitter phenotype plasticity in cultured dissociated adult rat dorsal root ganglia: an immunocytochemical study. J Neurosci Res 1989:22:473-8.

27. McCarhy PW, Lawson SN. Cell type and conduction velocity of rat primary sensory neurons with substance P-like immunoreactivity. Neuroscience 1989;28: 745-53.

28. McCarthy PW, Lawson SN. Cell type and conduction velocity of rat primary sensory neurons with calcitonin gene-related peptide-like immunoreactivity. Neuroscience 1990;34:623-32.

29. Nagy JI, Hunt SP. Fluoride-resistant acid phosphatasecontaining neurones in dorsal root ganglia are separated from those containing substance $\mathrm{P}$ or somatostatin. Neuroscience 1982;1:89-97.

30. Sterne GD, Brown RA, Green CJ, Terenghi G. NT-3 modulates NPY expression in primary sensory neurons following peripheral nerve injury. J Anat 1998;193:27381.

31. Verge VMK, Richardson PM, Wiesenfeld-Hallin Z, Hokfelt T. Differential influence of nerve growth factor on neuropeptide expression in vivo: A novel in peptide supression in adult sensory neurons. J Neurosci 1995;15:2081-96.

32. Price J, Mudge A. A subpopulation of rat dorsal root ganglion neurones is catecholaminergic. Nature 1983;301:241-3.

33. Sann H, McCarthy PW, Mader M, Schemann M. Choline acetyltransferase immunoreactivity in small diameter neurones of the rat dorsal root ganglion. Neurosci Lett 1995;198:17-20.

34. Prabhakar E, Lawson SN. The electrophysiologica properties of rat primary afferent neurones with carbonic anhydrase activity. J Physio 1995;482.3:609-22.

35. Wong V, Barrett C, Donati E, Eng L, Guth L. Carbonic anhydrase activity in first-order sensory neurons of the rat. J Histochem Cytochem 1983;31:293-300.

36. Vesin MF, Droz B. Immunodetection of prostaglandin D synthase: Conditions of localization in a defined subclass of primary sensory neurons. J Histochem Cytochem 1995;43:681-7.

37. Mannes LM, Kastin AJ, Weber JT, Banks WA, Beckman BS, Zadina JE. The neurotrophins and their receptors: Structure, function, and neuropathology. Neurosci Bionehav Rev 1994;18:143-59.

38. Rich KM. Neuronal death after trophic factor deprivation. J Neurotrauma 1992;9:s61-9.

39. Averill S, McMahon D, Clary O, ReicharD L, Priestley, $\mathrm{V}$. Immunocytochemical localization of trk $A$ receptors in chemically identified subgroups of adult rat sensory neurons. Eur J Neurosci 1994;7:1484-94.

40. Kashiba H, Noguchi K, Ueda Y, Serisa E. Coexpression of trk family members and low affinity neurotrophin receptors in rat dorsal root ganglion neurons. Mol Brain Res 1995;30:158-64

41. Kashiba H, Ueda Y, Ueyama T. Nemoto K, Senba E. Relationship between BDNF- and trk-expressing neurones in rat dorsal root ganglion: An analysis by in situ hybridization. Neuroreport 1997;8:1229-34.

42. Bergman E, Johnson H, Zhang Xu, Hokfelt T, Ulfhake B. Neuropeptides and neurotrophin receptor mRNAs in primary sensory neurons of aged rats. J Comp Neurol 1996;375:303-20.

43. Boyd RT, Jacob MH, McEacherm AE, Caron S, Berg D. Nicotinic acetylcholine receptor RNAm in dorsal root ganglion neurons. J Neurobiol 1990; 22:1-14.

44. Bowie D, Feltz P, Schlichter R. Subpopulations of neonatal rat sensory neurons express functional neurotransmitter receptors which elevate intracellular calcium. Neuroscience 1994;58:141-9.

45. Huang L, Neher E. Ca2+-dependent exocytosis in the somata of dorsal root ganglion neurons. Neuron 1996;17:135-45.

46. DeLeón M, Coveñas R, Chadi G, Narváez JA, Fuxe K, Cintra A. Subpopulations of primary sensory neurons show coexistence of neuropeptides and glucocorticoid receptors in the rat spinal and trigeminal ganglia. Brain Res 1994;636:338-42.

47. Duce IR, Keen P. Selective uptake of $(3 \mathrm{H})$ glutamine and $(3 \mathrm{H})$ glutamate in neurons and satellite cells of dorsal root ganglia in vitro. Neuroscience 1983;8: 861-6.

48. Cangro C, Sweetnam PM, Wrathall J, Haser W, Curthoys N, Neale J. Localization of elevated glutaminasa immunoreactivity in small DRG neurons. Brain Res 1985;336:158-61.

49. Jozsa R, Korf H, Merchenthaler I. Growth hormonereleasing factor (GRF)-like immunoreactivity in sensory ganglia of the rat. Cell Tissue Res 1987;247:441-4.

50. Kai-kai MA, Keen P. Localization of 5-hydroxytriptamine to neurons and endoneurial mast cells in rat sensory ganglia. J Neurocytol. 1985;14:63-78.

51. Spicer SS, Schuite BA. Abundance and diversity of glycoconjugates visualized cytochemically in the nervous system. Acta Histochem Cytochem 1995; 1:85-91.

52. Regan LJ, Dodd J, Barondes SH, Jessell TM. Selective expression of endogenous lactose-binding lectins and lactoseries glycoconjugates in subsets of rat sensory neurons. Proc Natl Acad Sci USA 1986;83:2248-52.

53. Nagao $\mathbf{M}$, Oka N, Kamo H, Akiguchi I, Kimura J. Differential localization of lectin binding sites and 
neuropeptides in human dorsal root ganglia. Histochemistry 1994;102:279-86.

54. Stucky CL, Lewin GR. Isolectin B4-positive and negative nociceptors are functionally distinct. J Neurosci 1999;19:6497-505.

55. Bennet DL, Michael GJ, Ramachandran N, Munson JB, Averill S, Yan Q, et al. A distinct subgroup of small DRG cells express GDNF receptor components and GDNF is protective for these neurons after nerve injury. J Neurosci 1998;18: 3059-72.

56. Dodd J, Solter D, Jessell TM. Monoclonal antibodies against carbohydrate differentiation antigens identify subsets of primary sensory neurones. Nature 1984; 311:469-72.
57. Matsumoto, S, Schneider LG, Kawal A, Yonezawa T. Further studies on the replication of rabies and rabieslike viruses in organized cultures of mammalian neural cells. J Virol 1974;61:981-96.

58. Castellanos J, Martínez M, Acosta O, Hurtado $\mathbf{H}$. Nerve growth factor and neurotrophin-3 modulate the rabies infection of adult sensory neurons in primary cultures. (En prensa).

59. Terenghi G. Peripheral nerve regeneration and neurotrophic factors. J Anat 1999;194:1-14.

60. Fu SY, Gordon T. The cellular and molecular basis of peripheral nerve regeneration. Mol Neurobiol 1997;14:67116. 